\title{
EVALUATION OF THE DATA APPLICABLE FOR DETERMINING THE ROUTES OF MOVEMENTS OF MILITARY VEHICLES IN TACTICAL OPERATION
}

\author{
Dana KRISTALOVA, \\ University of Defence, Brno, Czech Republic, \\ dana.kristalova@unob.cz
}

\begin{abstract}
War Conflicts in the past twenty years have shown the need to digitalize the battlefield. The commander needs a lot of input data for his right decision. These data are necessary for an automated decision-making process. For the successful planning of routes of movement, whether in peace or combat conditions, it is required to know the terrain and at the same time the use of algorithms for finding the correct paths. The determination of the level of Cross-Country Movement (abbr. CCM), or also the traffic ability of the terrain, is the basis for this right decision. Analysis of the Cross-Country Movement means the assessment of several geographical and tactical, technical and human factors together, i.e. that it is multi-criterial analysis. Finding the optimal path based on specified criteria (security, distance, economic cost, time) is not a trivial matter and therefore testing road conditions in the field is carried out. These tests validate the previous calculations.
\end{abstract}

\section{Keywords: geographical data, optimization of routes, movement of vehicles in terrain}

\section{Introduction}

The influence of the land cover on the movement of the military vehicles is very significant issue in military operation. Planning of the movements should be difficult question because the determination of the resulting solution is based on many of the input factors, particularly on the geographical, tactical and human factors and on tactical and technical data of vehicles. These factors are varying in time and they are mutually dependent.

\section{What is necessary to examine?}

The data and methodology for evaluation of Cross-Country Movement are basic issues.

\subsection{Data}

Geographical factors include relief, microrelief, vegetation, soils, waters, weather conditions, settlements and roads and paths. 


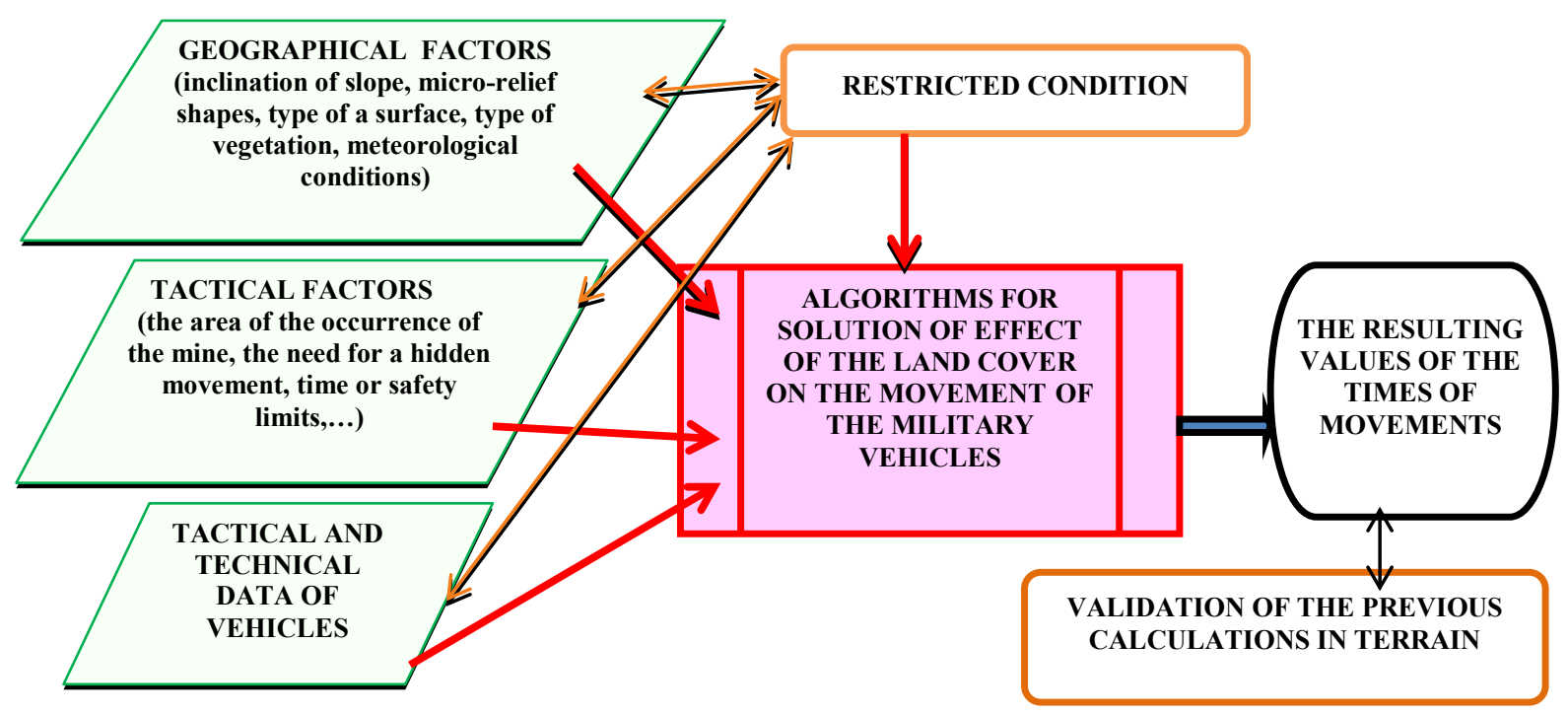

Figure 1: Scheme illustrates the system of determination of influence of surface on the movement of military vehicles. An effect of drivers as the human factor, limited financial, material and time resources, and other officials are among limiting condition.

The tactical factors are as follows: the deployment of own and foreign troops, the use of visible and hidden areas for observation, the conditions for the spread of fumes, the danger of minefields etc.

The tactical and technical data about vehicles that determine their ability to ride across the terrain are the third type of the data. See Fig.1.

\subsection{How to obtain the data?}

There are a lot of data sources. Map resources are a lot, but not all are suitable or sufficient.

The map data (analogue or digital), aerial or satellite images or textual evaluations, in most cases, can be used to obtain data on the Earth's surface or the individual components of the geo-sphere. But microrelief shapes are currently mapped only very weakly and, in any case, it is not sufficient for the evaluation of the possible running speed of vehicles. Also the information on the density of the forest cover or on other vegetation, the height of the trees and the diameters of the tribes is missing. Map resources are recommended only for evaluation of macro-relief and soil conditions.

Aerial laser scanning (Aerial Laser Scanning-ALS) is a very suitable and promising method for the inspection of an unknown, unavailable terrain or for the ,nodata area". This method can be very beneficial, especially in connection with the use of UAVS or UGV and with implementation of the geographical data can be realized even in tactical systems (whose use is intended to in the future in resolving conflicts). Such a system is e.g. C4ISTAR.The connection of the air laser scanner and remote controlled carriers was evaluated as the best method of obtaining data. The current data are taken almost in real time, detailed (micro-relief is recorded), and after processing using special SW data allows wide use for mathematical modelling and simulation of real terrain.

Geodetic measurements are used only for indicative evaluation of the surface roughness and are inefficient. Employment of various other methods such as penetration-metric measurement or the use of radar imagery is particularly suitable for the detection of soil properties.

\subsection{Cross-Country Movement}

These factors and their standards determine 3 levels of Cross-Country Movement - GO, SLOW GO and NO GO. The level called "GO" means the movement without loss of 
speed, the level "SLOW GO" means partial deceleration of the speed of the movement and the last level "NO GO" stands for the fact that the movement is not possible. These terms are given by NATO Standards [1] and this issue is generally mentioned in several other publications [2,3].

\section{Evaluation of CCM}

There are several ways of providing a solution. It is necessary to obtain the data about the type and sort of soil, temperature and moisture and the times of the duration of the test routes in various fields in digital form. The Cross-Country Movement, in particular the influence of soils, micro-relief shapes and weather conditions and the correct determination of movements, is the main contents of the dissertation [4] and it is mentioned in $[5,6]$.

\subsection{Coefficient of Deceleration}

Thanks to the joint assessment of these factors and their standards indicating the degree of the Cross-Country Movement, it is possible to calculate the coefficient of the deceleration (abbrv. CoD) and it is feasible to determine the correct route of movement for various military units.

The common impact of GF on the deceleration of vehicle movement at given section of route can be expressed by the following algorithm $[2,3]$ :

$v_{j}=f\left(v_{\max }, c_{1}, c_{2}, \ldots c_{n}\right)$

where,

$v_{j}=$ vehicle speed at $j$-section of vehicle path

$\mathrm{v}_{\max }=$ maximum road speed

$c_{i}=i$-coefficient of deceleration due to factor $F_{i}$ computed for $j$-section with invariable values $c_{i}$ $\mathrm{n}=$ number of geographical factors effecting at given section of the terrain

$\mathrm{k}=$ number of section on vehicle path

The total CoD depends on the partial CoD of the different GF and is given by this formula $[3,4]$ :

$$
C=\prod_{i=1}^{8} c_{i}
$$

where, $\mathrm{C}=$ total $\mathrm{CoD}$ and $\mathrm{c}_{\mathrm{i}}=$ partial CoD.
These basic algorithms were particularized by a huge number of measurements, data processing and calculations. The authors tried to depict all the important links of the GF. A large number of field tests were realized, and thus, it was possible to include real (not only laboratory or theoretical) measurement.

\subsection{Principle of Value map}

The use of the study "The influence of relief and micro-relief on the traffic ability of the territory by selected military vehicles" [7] was verified.

The procedure of calculations of increase lengths on the track due the obstacles (that are given by partial values of the length, heights and angles of each micro-relief shapes) is discussed in the study. The study mentions the use of the principle of value maps. The entire area of interest is divided into partial face-pixels. Data on longitudinal and transverse inclination of rolling resistance coefficient and adhesion are assigned these pixels.
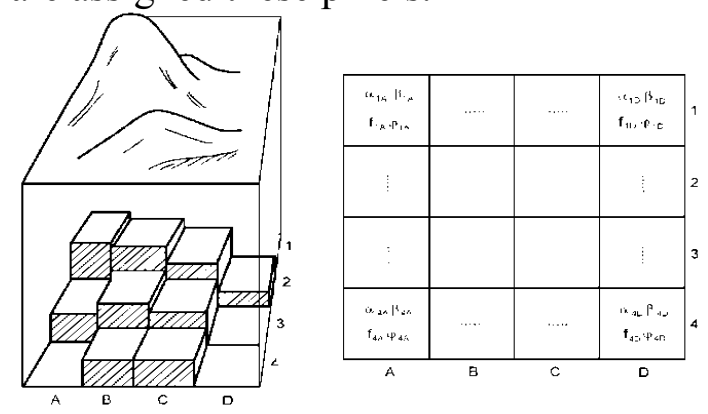

Figure 2: The principle of price maps, when a value is assigned to each cell.

The methods for calculation of longitudinal and transverse inclination are also included. The use of this method (raster format) would be for the intended IS convenient, but again, there is the question of the data details: at present, no data model (that would define the distribution of the microrelief shapes on the track) is implemented.

\subsection{Algorithms in $\mathrm{C}^{++}$}

A model simulating the ride vehicles in the field has been created in the programming language $\mathrm{C}++$.

The input data defining the profile field 
curve was obtained by two methods - by terrestrial laser scanning or (measurement of the coordinates of the profile was targeted with step $10 \mathrm{~cm}$ ) and by total station Leica (characteristic fracture points of terrain shapes in the same profile were targeted on the basis of a subjective selection of meters). Length and height coordinates were used.

Several algorithms have been built. Their purpose was: to retrieve data, to display the off-road curve refining the methodology of the rolling wheel after the terrain and the final output, to determine the value of the time needed to complete the profile.

Other input data were maximum vehicle speed, wheel diameter, the maximum speed of the vibrations in the wheels - always relevant to a given type of vehicle. Here, the problems with the unavailability of data has arisen, which was eventually resolved thanks to the contribution of the workers of the Development Department of the company Tatra in Kopřivnice. Linking these data and the results exported from simulation models created in the workplace at University of Defence in SW ADAMS, as well as other sources of data for the simulation models in the programming language $\mathrm{C}++$. For samples of simulation models, see figure 3 . The issue of the optimization of routes and calculation of algorithms and coefficients is mentioned in $[8,9,10,11]$. The movements may be with the use of communication or without it. Movements outside the communication can be used, for example, for ambulances or if the floods occur.

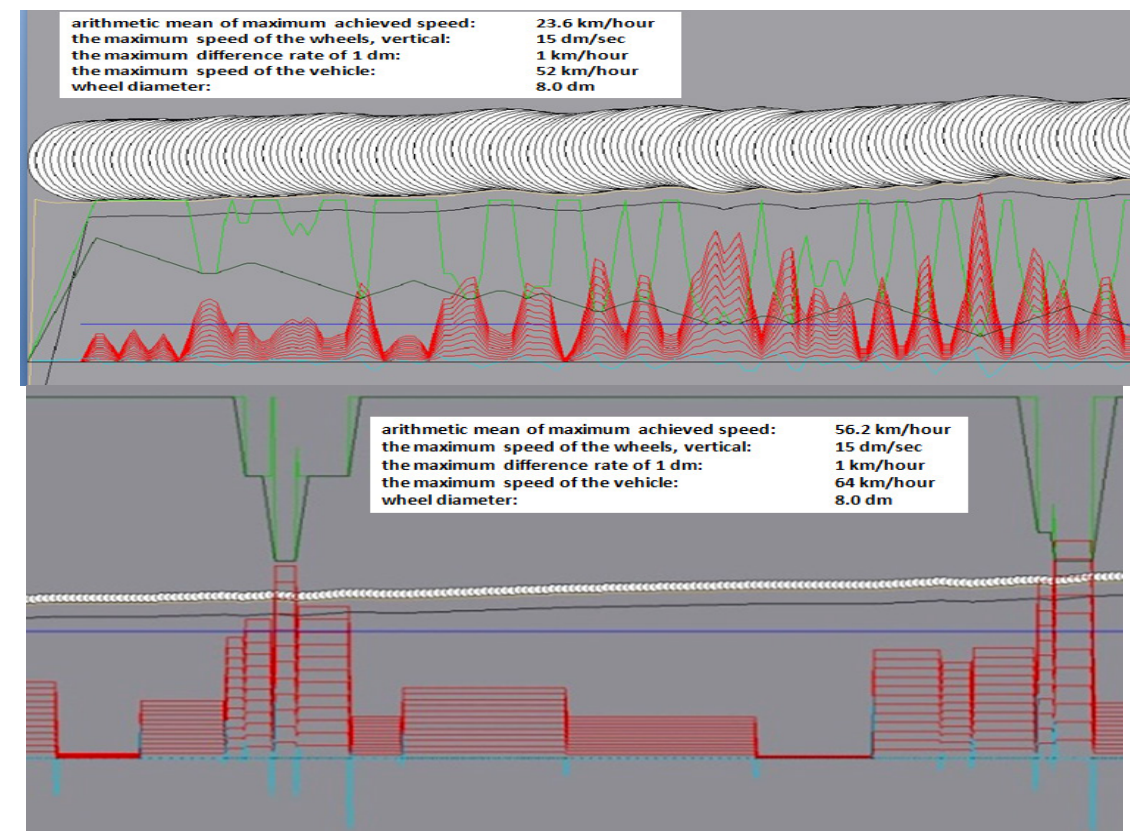

Fig. 4: Samples of an estimate of a calculation of time moving in the model in a programming language $C^{++}$. On both figures the issue of the rolling wheel on real terrain (the black curve under the wheel) and on the substitute terrain (the yellow curve under the wheel) is illustrated. The results of the calculation algorithms for actual speed are the red curve, the maximum speed of oscillation wheels as the dark blue curve, the maximum actual speed as a green and the maximum possible speed profile

limited convolution filter is rendered dark green (it is a pyramid-shaped).

On the upper figure there is the profile of the track in the model of terrain obtained by method of laser scanning. The estimated speed was set at $23.6 \mathrm{~km} / \mathrm{hour}$. This estimate was precise - the time difference in relevant terrain was about $0.5 \mathrm{~km}$ per hour.

On the bottom figure there is a sample section, where the input data was obtained by geodetic method and the selection of reversal points is influenced by the subjective selection of a worker. The lengths of the breaklines are (with respect to the inequality of the ground) approximately 5 meters and more, which does not allow the accurate use of the model. The estimated speed was set at $56.2 \mathrm{~km} / \mathrm{hour}$. But in real rides the maximum average speed of $32 \mathrm{~km} / \mathrm{h}$ was achieved. 
The movements may be realised with the use of communication or without it. Movements outside the communication can be used, for example, for ambulances or if floods occur. The evaluation of tactical features and other criteria are mentioned in $[12,13]$.

\section{Results}

Many field experiments in different types of terrain were done. These tests verified estimates of the times of rides that provide the model created in the programming language $\mathrm{C}^{++}$. These results are in Table 1 . There are listed the types of vehicles, names of testing areas, roughness factor, inclination and speeds of vehicles relevant to the mentioned parameters that were achieved. Roughness factor is a value from 1 to 5 that signifies an amount of microrelief shapes. The influence of micro-relief shapes was calculated by a mathematical procedure - by tool "variation of function" (see [12]).

It is obvious that the speed of vehicles in the field is most affected by the amount of the relief, then by the meteorological conditions in combination with the soil types. The resulting speed was selected as the median i.e. middle value.

Table 1 The resulting values of the times rides from field testing

\begin{tabular}{|c|c|c|c|c|c|c|c|c|c|c|c|c|c|c|c|c|c|c|c|c|}
\hline \multicolumn{5}{|c|}{ Types of Vehicle } & \multicolumn{4}{|c|}{ LR-110 } & \multicolumn{4}{|c|}{ UAZ 469} & \multicolumn{4}{|c|}{$T-810$} & \multicolumn{4}{|c|}{ PANDUR II } \\
\hline $\begin{array}{c}\text { Name of } \\
\text { the Track }\end{array}$ & 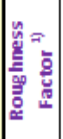 & $\begin{array}{l}\text { Type of } \\
\text { Surface }\end{array}$ & 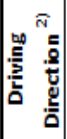 & 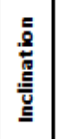 & 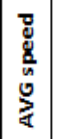 & 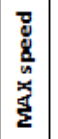 & 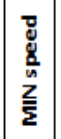 & 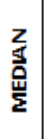 & 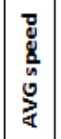 & 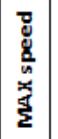 & 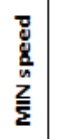 & 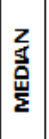 & 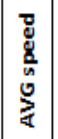 & 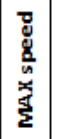 & 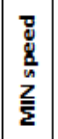 & 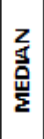 & 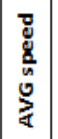 & 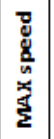 & 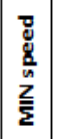 & 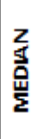 \\
\hline \multirow{2}{*}{$\begin{array}{c}\text { Ploughed Field } \\
\text { (not smooth due } \\
\text { to the rides) }\end{array}$} & \multirow{2}{*}{5} & \multirow{4}{*}{ MUDS+SAND } & $E A$ & 2,1 & 17,1 & 21,2 & 12,8 & 17 & 14,1 & 18,9 & 12,9 & 16 & & & & & & & & \\
\hline & & & ED & $-2,1$ & 16,1 & 24,2 & 14,0 & 16 & 14,5 & 16,5 & 11,8 & 16 & & & & & & & & \\
\hline \multirow{2}{*}{$\begin{array}{c}\text { Ploughed Field } \\
\text { (smooth due to } \\
\text { the rides) }\end{array}$} & \multirow{2}{*}{4} & & EA & 2,0 & 20,5 & 33,1 & 17,4 & 22 & 22,1 & 26,0 & 17,5 & 22 & & & & & & & & \\
\hline & & & ED & $-2,0$ & 19,7 & 34,0 & 18,3 & 21 & 23,5 & 27,6 & 22,7 & 24 & & & & & & & & \\
\hline \multirow{6}{*}{$\begin{array}{c}\text { Tank Training } \\
\text { Area }\end{array}$} & \multirow{2}{*}{5} & \multirow{2}{*}{ MUDS+SAND } & $F$ & 0,7 & 30,4 & 34,0 & 28,3 & 30 & 32,2 & 34,9 & 28,8 & 33 & 16,0 & 17,1 & 13,1 & 16 & 19,1 & 20,0 & 17,4 & 19 \\
\hline & & & $\mathrm{F}$ & $-0,7$ & 31,1 & 36,5 & 28,0 & 31 & 34,2 & 37,6 & 28,5 & 36 & 17,8 & 19,3 & 15,4 & 18 & 19,2 & 19,9 & 17,5 & 19 \\
\hline & \multirow[t]{2}{*}{5} & \multirow{2}{*}{ CLAY+SNOW } & EA & 2,1 & 22,0 & 23,3 & 19,0 & 23 & 30,9 & 32,0 & 29,8 & 31 & 18,0 & 19,4 & 15,6 & 18 & 19,9 & 21,7 & 17,0 & 21 \\
\hline & & & ED & $-2,1$ & 21,6 & 22,3 & 20,8 & 22 & 29,3 & 30,7 & 27,0 & 30 & 19,0 & 20,2 & 17,5 & 19 & 21,3 & 22,9 & 19,0 & 22 \\
\hline & \multirow{2}{*}{5} & \multirow{2}{*}{ CLAY+SNOW } & EA & 1,9 & 26,9 & 29,2 & 23,9 & 28 & 30,2 & 25,7 & 28,0 & 32 & & & & & & & & \\
\hline & & & ED & $-1,9$ & 25,5 & 27,0 & 23,3 & 26 & 29,4 & 30,9 & 28,0 & 29 & & & & & & & & \\
\hline \multirow{2}{*}{ Open Terrain } & \multirow{2}{*}{4} & \multirow{2}{*}{ CLAY } & \multirow{2}{*}{ EA } & \multirow{2}{*}{1,4} & 28,1 & 30,0 & 25,0 & 29 & 27,4 & 28,6 & 24,7 & 28 & 25,7 & 27,7 & 23,7 & 26 & 30,9 & 31,6 & 30,0 & 31 \\
\hline & & & & & 24,9 & 25,7 & 24,3 & 25 & 24,0 & 25,0 & 22,8 & 24 & 23,0 & 24,0 & 21,7 & 23 & 27,5 & 28,6 & 26,5 & 28 \\
\hline Open Terrain & 3 & CLAY & A & 3,4 & 31,3 & 32,0 & 30,3 & 31 & 31,0 & 32,0 & 29,8 & 31 & 23,9 & 27,4 & 22,7 & 23 & 32,2 & 33,9 & 30,9 & 32 \\
\hline & & & & & 30,1 & 30,9 & 29,3 & 30 & 30,2 & 31,4 & 29,3 & 30 & 23,2 & 25,0 & 22,4 & 23 & 31,5 & 32,6 & 30,9 & 31 \\
\hline & 4 & CLAY+ & $\mathrm{F}$ & 0,0 & 23,7 & 25,4 & 22,5 & 24 & 33,6 & 36,0 & 28,0 & 34 & 26.8 & 32.2 & 211 & 27 & 40,1 & 48,1 & 32.4 & 41 \\
\hline Meadow & & & & & 22,6 & 24,5 & 19,7 & 23 & 31,0 & 34,6 & 23,3 & 33 & & & & & & & & \\
\hline & 4 & SAND+GRASS & D & $-0,7$ & 19,9 & 18,9 & 21,2 & 21 & & & & & 17,8 & 21,0 & 15,5 & 17 & & & & \\
\hline Sandy Path & 1 & SAND & $\mathrm{F}$ & \begin{tabular}{|l|}
$-0,3$ \\
\end{tabular} & 23,7 & 24,9 & 23,5 & 24 & 23,7 & 24,9 & 23,5 & 24 & 27,3 & 33,2 & 17,2 & 30 & & & & \\
\hline Paved Path & 2 & GRITS & $\mathrm{F}$ & $-0,5$ & 32,9 & 36,5 & 28,6 & 33 & 32,9 & 36,5 & 28,6 & 33 & 31,8 & 38,7 & 27,7 & 32 & & & & \\
\hline Forest & 2 & CLAY & A & 5,6 & 36,6 & 48,4 & 28,9 & 35 & 37,1 & 39,5 & 30,9 & 38 & 32,8 & 34,5 & 27,9 & 34 & 24,9 & 25,3 & 23,0 & 25 \\
\hline (paved) Path & & & D & $-5,6$ & 35,9 & 46,3 & 28,9 & 34 & 46,8 & 48,4 & 41,0 & 47 & 36,8 & 38,1 & 33,4 & 37 & 35,4 & 36,0 & 34,8 & 35 \\
\hline Grass Slope & 2 & SUNDY+MUD & A & 6,4 & 29,5 & 34,3 & 26,4 & 28 & 26,4 & 27,1 & 25,7 & 20 & & & & & & & & \\
\hline & & & D & $-6,4$ & 43,1 & 49,8 & 35,6 & 47 & 38,0 & 40,1 & 32,4 & 38 & & & & & & & & \\
\hline & 1 & COBBLED & A & 15,0 & & & & & & & & & 14,2 & 18,8 & 8,5 & 15 & 12,0 & 13,8 & 8,5 & 13 \\
\hline Cobbled Slope & 1 & & D & $-15,0$ & & & & & & & & & 14,6 & 15,4 & 8,2 & 16 & 7,4 & 14,5 & 6,4 & 13 \\
\hline & 1 & COBBLED & A & 20,0 & & & & & & & & & 13,5 & 18,8 & 17,1 & 18 & 7,4 & 8,0 & 6,4 & 7 \\
\hline & & & D & $-20,0$ & & & & & & & & & 15,5 & 21,9 & 20,2 & 21 & 13,3 & 14,4 & 12,4 & 13 \\
\hline Road in & 1 & CONCRETE & $\mathrm{F}$ & 0,3 & 46,7 & 48,0 & 44,8 & 47 & 45,1 & 46,2 & 44,9 & 45 & 43,8 & 43,8 & 42,7 & 44 & 42,9 & 44,0 & 42,0 & 43 \\
\hline summer & 1 & & $\mathrm{~F}$ & $-0,3$ & 47,2 & 47,7 & 46,3 & 47 & 45,5 & 46,9 & 44,2 & 45 & 44,9 & 46,6 & 42,9 & 46 & 44,9 & 45,8 & 43,8 & 45 \\
\hline Road in & 1 & CONCRETE + & $\mathrm{F}$ & 0,2 & 43,8 & 46,6 & 39,7 & 45 & 42,5 & 45,4 & 38,8 & 43 & 41,4 & 43,8 & 39,4 & 42 & 40,4 & 42,6 & 39,1 & 40 \\
\hline winter & & & $\mathrm{F}$ & $-0,2$ & 42,1 & 44,6 & 39,4 & 43 & 47,2 & 49,5 & 45,4 & 47 & 43,5 & 45,0 & 41,6 & 44 & 43,3 & 45,5 & 41,6 & 43 \\
\hline
\end{tabular}

\section{Conclusions}

The testing of the methodology is necessary as a practical verification. In order to obtain the correct method for calculating the speed of driving vehicles in the field when the speed is affected by the surface of the terrain, it is also necessary to select the correct method to get the correct data. The 
second step is to analyse the data and the third step is to identify ways to evaluate these data. The fourth step is to create algorithms for the calculation of time limits movements. Algorithms could be used to modify other aspects (economic, security or terms of the shortest distance).

The method of obtaining input data may be different. The author is trying to find the most modern ones. The terrestrial laser scanning is not a suitable method for all types of surfaces. The measurement of the changes to the surface thanks to vehicles driving through the field was not accurate. Sod grass and clods of dirt have been distractive elements, which distort the tracked vehicles. The terrestrial laser scanning is not really a suitable method for the grass and clay surfaces. Vice versa, sandy surfaces have a different structure, and the results could be very accurate. This type of surface shall be measured in the future. It is apparent that the methods of measurement of input data and the evaluation of the models of surfaces are not identical; they are dependent on dissimilarity of surfaces. However, unlike other methods, for example the geodetic method, this data is very detailed and so it allows calculation time estimates, using mathematical algorithms movements. This fact is very significant.

The researchers in the foreign armies devote a lot of interest to this problem too, but the results of their work are restricted mostly to bringing up the topic for discussion.

The result of a research that is pursued at the University of Defence in Brno in the Czech Republic will be a proposal for a digital interface for the collection, management, creation of additional analyses and redistribution of geographic data. For the new information system, supporting documents containing database about tactical and technical data of vehicles would be necessary. It is convenient to use the cooperation with experts from the field of automotive technology.

This aspect of the fullness database data elements is an open question, however, due to the development of methods and devices for data collection. It is assumed that in the future the current terrain problem will not be ignored.

\section{Acknowledgements}

The work presented in this paper has been supported by the Ministry of education, youth and sports of the Czech Republic (research project SV15-FVL-K110-10-KRI).

\section{References}

[1] STANAG 3992 - AgeoP-1 Terrain Analyses, Field manual No. 5-33, Headquarters Department of the Army US, Washington, 1990.

[2] Procedural Guide for Preparation of DMA Cross-Country Movement (CCM) Overlayes, Defence Mapping School, Fort Belvoir. Virginia, 396 p., 1993.

[3] RYBANSKY, Marian, Cross-Country Movement, The Impact and Evaluation of Geograpfical Factors, Brno, Academic publishing CERM, s.r.o., 2009. 114 pp. ISBN 978-80-7204-661-4

[4] KRISTALOVA, D., The influence of the land cover on the movement of the military vehicles (Dissertation), University of Defence, Brno, Czech Republic, 209 p, 2013.

[5] KRISTAlOVA, D. An Effect of Sandy Soils on the Movement in the Terrain. In: MESAS. Rome, Italy: Springer International Publishing, 2014, ISBN 978-3-319-138237, pp. 262-273.

[6] KRISTALOVA, D., MAZAL, J. The Effect of Land Cover on Movement of Vehicles in the Terrain. In: Proceedings ICESSE 2014: International Conference on Earth and Space Sciences and Engineering, London, United Kingdom, (Nov 28-29, 2014). London, United Kingdom: World Academy of Science, Engineering and Technology, 2014, ISSN 13076892, pp. 210-215. 
[7] VALA, Miroslav, Evaluation of terrain vehicle passability (in Czech), Hodnocení průchodivosti terénních vozidel, Brno, VA, 152 p., 1992.

[8] KRISTALOVA, D.: An evaluation of methods of optimization of movement routes according to tactical aspects of the combat operation planning process Proceedings of International Scientific Conference ICMT, 2011, Brno, 8p., ISBN: 978-80-7231-787-5.

[9] KRISTALOVA, D. The overview of existing digital data and GIS used in the Army of the Czech Republic and their possible use in tactical-geographic analysis, Proceedings of International Scientific Conference MMK, Czech Republic, 2011, ISBN:978-80-904877$7-2,8 \mathrm{~s}$

[10] MAZAL, Jan, The algorithms of the effect of geographical factors on the optimal movement of military vehicles in terrain and at the communication (in Czech), UO Brno, 2009, 87 pp];

[11] MAZAL, J.: Real time maneuver optimization in general environment. Berlin : Springer Berlin Heidelberg, 2010, p. 191-196. Recent Advances in Mechatronics. ISBN 978-3642-05021-3.

[12]KRISTALOVA, D., MAZAL, J.; NEUBAUER, J. New approaches to the determination of the time costs of movements. In: ABSRC 2014 MILAN - Advances in BusinessRelated Scientific Research Conference. Milan, Italy: GEA COLLEGE, 2014, p. 1-12. ISBN 978-961-6347-55-6.

[13]KRISTALOVA, D. The contribution of the methods of terrestrial laser scanning to evaluation of the impact on movement of military vehicles Proceedings of International Scientific Conference. IDEB Bratislava, Slovakia, 2012, ISBN 978-80-8075-525-6, 8 pp. 